\title{
Farmers' Willingness to Participate in Small-Scale Farmland Water Conservation Construction in China
}

\author{
Fang Luo ", Fangmin Sun, Dan Xu, Caihong Sun, Qing Wang \\ School of Commerce, Huanggang Normal University, Huanggang, China \\ Email address: \\ 1098243781@qq.com (Fang Luo),282565749@qq.com (Fangmin Sun),290651528@qq.com (Dan Xu), \\ suncaihong@163.com (Caihong Sun),ham2571@163.com (Qing Wang) \\ ${ }^{*}$ Corresponding author
}

\section{To cite this article:}

Fang Luo, Fangmin Sun, Dan Xu, Caihong Sun, Qing Wang. Farmers' Willingness to Participate in Small-Scale Farmland Water Conservation Construction in China. International Journal of Economic Behavior and Organization. Vol. 5, No. 2, 2017, pp. 54-62.

doi: $10.11648 /$ j.ijebo.20170502.12

Received: February 21, 2017; Accepted: March 13, 2017; Published: March 15, 2017

\begin{abstract}
Small-scale farmland water conservation facilities are "the last mile" of irrigation works, and determine whether the large- and medium-scale water conservation projects financed by the government will provide the most value and maximum efficiency. Farmers play a primary role in the construction of small-scale farmland water conservation, while the government's role is only to encourage and subsidize such projects. Farmers' willingness to participate determines their behavior. This paper, firstly, uses a utility function for goods and water conservation facilities to solve the farmers' optimization problem. It puts forward six theoretical propositions about farmers' willingness to invest in small-scale farmland water conservation. Secondly, based on survey data in Hubei Province, China, the Heckman Two-step Model is used to analyze the factors affecting farmers' willingness to participate in construction of small-scale irrigation systems and the factors affecting the amount of investment that participants are willing to undertake.
\end{abstract}

Keywords: Heckman Two-Step Model, Small-Scale Farmland Water Conservation, Farmers

\section{Introduction}

Irrigation is important to national food security in China. China's gross output of grain was $621,435,000$ tons in 2015 , an increase of $2.4 \%$ over the previous year. This was the 12 th consecutive increase in grain output from 2004 to 2015 [1]. Grain production has been above $350 \mathrm{~kg} /$ person since 1980 [2], close to the world average level. China uses only $9 \%$ of the world's cultivated land to feed $22 \%$ of the world's population. In China, the irrigated areas, which are less than half of the total cultivated areas, produce $75 \%$ of the nation's grains and $90 \%$ of its commercial crops, such as cotton and vegetables [3]. The 2011 No. 1 document of the Central Committee of China explicitly put the construction of farmland water conservation at the strategic height of national food security. As a result, the government has increased direct investment in large- and medium-scale water conservation facilities. Subsidies for small-scale farmland water conservation have increased progressively over the years, and construction of small-scale farmland water conservation in key counties has sped up. In the meantime, through institutional and market-oriented reforms, the government has been promoting new investors' participation in water conservation construction [4]. The small-scale irrigation systems, directly applied to the fields, are called "the last mile" of water conservation facilities. Generally, the scale of this type of facility is small, with an irrigation area of less than $666.7 \mathrm{hm}^{2}$, surface drainage area less than $2000 \mathrm{hm}^{2}$ and channel flow less than $1 \mathrm{~m}^{3} / \mathrm{s}$ [5].

Farmers' participation in the construction of small-scale farmland water conservation is called participatory irrigation management (PIM) or irrigation management transfer (IMT) by many scholars. The related research includes five main aspects. The first is water pricing policy. There are three points of view about whether water pricing policy can realize the goal of water conservation. The positive view suggests that a 
pricing mechanism can be used for the effective management of water resources [6]. For example, Berbel and Gómez-Limón think that an appropriate increase in water price leads peasants to realize the scarcity of water resources and to adopt water-saving technologies on the premise of not affecting their choices of which crops to plant and when to plant [7]. A negative view is proposed by Aregay et al. [8]. Through water consumption and fertilizer input, they estimate the effect of a pricing policy on environmental sustainability. Their results show that the policy of managing water demand has little effect on the regional environment and leads to a decrease in farm income and crop varieties and an increase in direct and indirect unemployment. A third view, i.e., a compromise view, e.g., Bartolini et al. [9], proposes that water price has inconsistent effects on different objectives and interest groups.

The second research topic is the investment mechanism for the construction of farmland water conservation. In developed countries and regions, the government bears most of the costs for the construction of farmland water conservation, but, in developing countries and less-developed regions, private organizations and farmers undertake more costs [10]. The responsibility for investment in water resources may be allocated according to the share of water used, the order in which water is taken, or the irrigated area [11]. Farmers' willingness to invest is higher when water distribution rules are made through a system that includes most people in a village, compared to rule-making by government agencies or rural elites [12]. For instance, Sarker and Itoh find that decision making is very successful in Japan's Land Improvement Districts (LID) due to the rich social capital in Japan [13]. In that case, large-scale water conservation projects are constructed by the government, while small-scale projects are undertaken by LID and the government. For small-scale farmland water conservation projects in Japan, the government is mainly responsible for the physical supply, and, once completed, over $80 \%$ of the work of operation and management is transferred to LID.

The third research topic concerns the benefits of farmland irrigation in terms of output. Brown and Halweil compare the effects of irrigation and natural precipitation on Chinese and American grain production capacity [14]. In America, only 10\% of grain yield comes from irrigation, while, in China, more than $70 \%$ of grain production is dependent on irrigation. Huang et al. show that crop income in China is highly related to irrigation [15]. Increasing irrigated land by one hectare per capita will lead to an increase of 3,082 RMB in annual cropping income per capita. The spread of irrigation contributed between 50 and 60 percent of the massive increase in agricultural output of the developing countries from 1960 to 1980 [16].

The fourth topic concerns the structure of governance and the performance of farmland water conservation projects. The governing structure of farmer participation in irrigation management can bring permanent benefits and have potent effects, and transferring partial or complete management responsibility from the government to peasant associations or other private entities is effective [17]. The co-management model of cooperation between water users and the government increases the benefits of farmland water conservation projects [18]. Meinzen-Dick finds that the management of private pumping wells is more efficient than that of non-private pumping wells in Pakistan, which shows that privatization of project property rights can improve operating efficiency [19].

Finally, the fifth research topic is the farmers' willingness to participate in irrigation management. Kong and Shi put forward the idea that the probability of a farmer taking part in a Water User Association (WUA) is significantly positively related to the cultivated area of cash crops, irrigation area and ratio of agricultural expenditure to overall family expenditure, and is significantly negatively related to total cultivated area and the farmer's degree of satisfaction with current water conservation facilities [20]. Xu and Huang find that enlarging the scale of operation and the proportion of paddy field, stabilizing the contracted management rights for the land, or decreasing the degree of arable land fragmentation may significantly increase a farmer's willingness to participate in irrigation management [21].

To study farmers' willingness to take part in the construction of small-scale farmland water conservation, most researchers have used binary choice models, i.e., Probit Model, Logit Model, etc. [20] [22]. They analyze the factors that affect farmers' willingness to participate in the construction of small-scale farmland water conservation projects. However, this paper uses the Heckman Two-step Model (Heckman Model for short). Compared with the binary choice models, the Heckman Model has the advantage that it not only analyzes the factors that affect farmers' willingness to participate in the construction of small-scale farmland water conservation projects, but also reveals the effect of these factors on the proportion of the construction costs that participants are willing to invest.

This paper's content includes: theoretical analysis and propositions; data sources and descriptive statistics; model specifications and explanation of variables; model estimation and analysis of results; and conclusions and discussion.

\section{Theoretical Analysis and Propositions}

Assume that there are $n$ rural households, i.e., farmers in the village. The investment in small-scale farmland water conservation of farmer $k(k=1,2, \ldots, \mathrm{n})$ is $h_{k}$. The total facilities of the village small-scale farmland water conservation is $H=\sum_{k=1}^{n} l_{k} h_{k}+H_{0}+G_{0}$, in which $l_{k}$ is the impact factor, defined as the impact of the contribution of farmer $k$ to the construction of small-scale farmland water conservation; $H_{0}$ is the village's original stock of small-scale farmland water conservation; and $G_{0}$ is the government's current small-scale farmland water conservation investment. The budget constraint of farmer $k$ is $p_{x} x_{k}+p_{h} h_{k}=M_{k}$, in which $p_{x}$ and $x_{k}$ are the price and quantity, respectively, of 
a basket of goods consumed by a farmer; $p_{h}$ and $h_{k}$ are the total cost of small-scale farmland water conservation and the proportion of the investment contributed by a farmer, respectively; and $M_{k}$ is the family income. The farmer's utility function, $U_{k}$, takes the form of a Cobb-Douglas function, $U_{k}\left(x_{k}, H\right)=x_{k}^{a} H^{b} \quad$ [22], in which $a$ is the commodity demand elasticity of utility, i.e., a $1 \%$ change in $x_{k}$ causes a percentage change in $U_{k}$, and $b$ is the small-scale farmland water conservation demand elasticity of utility, or irrigation demand elasticity of utility for short, i.e., a $1 \%$ change of $H$ causes a percentage change in $U_{k}$. Taking the natural logarithm on both sides of the utility function yields $\ln U_{k}\left(x_{k}, H\right)=a \ln x_{k}+b \ln H$. Liu and Chen assumed $a+b \leq 1$ [22]. However, considering that the construction of farmland water conservation may improve farmers' utility, we relax this assumption and will test it. The optimization problem of a farmer is

$$
\operatorname{Max} \ln U_{k}\left(x_{k}, H\right) \text {, }
$$

\section{s. t. $p_{x} x_{k}+p_{h} h_{k}=M_{k}$}

The Lagrange function, $L=a \ln x_{k}+b \ln H+c\left(M_{k}-p_{x} x_{k}\right.$ $-p_{h} h_{k}$ ), is built, where $c$ is the Lagrangian multiplier. By the first-order condition, i.e., $\frac{\partial L}{\partial x_{k}}=0, \frac{\partial L}{\partial h_{k}}=0$ and $\frac{\partial L}{\partial c}=0$, it is obtained that

$$
h_{k}^{*}=\frac{1}{1+a / b} \frac{M_{k}}{p_{h}}-\frac{1}{1+\frac{1}{a / b}} \frac{1}{l_{k}}\left(\sum_{\substack{j=1 \\ j \neq k}}^{n} l_{j} h_{j}+H_{0}+G_{0}\right),
$$

where $j$ represents a farmer, and $h_{k}^{*}$ is the optimal solution of the farmer investing in small-scale farmland water conservation.

According to Equation (2), the propositions are put forward as follows:

Prop. 1 The higher the farmer's income, $M_{k}$, the more he invests in small-scale farmland water conservation.

Prop. 2 The greater the value of $a / b$, the less the farmer invests in small-scale farmland water conservation.

Prop. 3 The higher the price of small-scale farmland water conservation, $p_{h}$, the less the farmer invests in it.

Prop. 4 The larger the farmer's impact factor, $l_{k}$, the more the farmer invests in small-scale farmland water conservation.

Prop. 5 The greater the sum of the farmer's other investments, $\sum_{\substack{j=1 \\ j \neq k}}^{n} l_{j} h_{j}$, the original stock of water conservation in the village, $H_{0}$, and the current government investment, $G_{0}$, the less the farmer invests in small-scale farmland water conservation.

Prop. 6 The assumption of $a+b \leq 1$ fails.

The above six propositions are tested as follows.

\section{Data Sources and Descriptive Statistics}

Taking the form of a questionnaire survey, the data were collected from September to October, 2014. The respondents are farmers in Hubei Province, China, and the interviewee who answers the questions may be the head of a household or the primary labor supplier in the family. Hubei Province was selected as the research region because it is located in central China, is representative of thirteen major grain-producing provinces, and plays an important role in ensuring national food security. Its irrigation cultivated area is $2,855,300 \mathrm{hm}^{2}$, the rural population is $25,780,000$ persons, and per capita GDP is 47,124 RMB. It is a moderately developed region. Using encounter sampling, the survey distributed 300 questionnaires in total and yielded 277 effective questionnaires, i.e., the effective rate was $92.3 \%$.

The descriptive statistics of sampled farmers are shown in Table 1, and the mean, standard deviation, minimum and maximum of continuous variables are shown in Table 2 . The mean age of heads of households is 48.18 years. Their average years of schooling is 6.81 , i.e., less than graduation from junior high school, which shows that the education level does not meet the requirements of modern agricultural production. The average number of men below age 50 who are home year-round is 0.66 , so prime rural labor is significantly deficient. The mean annual income of a family is $36,970 \mathrm{RMB}$, only $6,500 \mathrm{RMB}$ of which is from agriculture, accounting for $17.6 \%$ of total income. Because the rate of agricultural return is low, more than $80 \%$ of a family's revenue comes from non-agricultural industries. The mean actual cultivated area of households is $0.38 \mathrm{hm}^{2}$, of which $0.16 \mathrm{hm}^{2}$ is dry land, accounting for $42.0 \%$, and $0.22 \mathrm{hm}^{2}$ is paddy fields, accounting for $58.0 \%$. This is too little to match the strategic responsibility of national food security that this major-grain producing province bears. There are four types of landform plain, hill, mountain and mound - accounting for 52.35\%, $30.69 \%, 22.02 \%$ and $7.22 \%$, respectively. Being long neglected and in disrepair, or inappropriately managed and protected, about $36.46 \%$ of farmland water conservation facilities have been destroyed and $21.30 \%$ of farmland suffers from a serious lack of irrigation. Because Hubei is "a province having thousands of lakes", at least $15 \%$ of farmers are rain-dependent. Private irrigation organizations, such as WUAs, are not popular. Only $5.42 \%$ of farmers say these organizations exist in the locality, and only $4.65 \%$ of farmers participate in them. About $61.73 \%$ of farmers trust the organizational capability and the clean administrative ethics of village cadres. About $83.03 \%$ of farmers are willing to participate in small-scale farmland water conservation projects, of which $63.91 \%$ want their participation to take the form of investing their labor, while $38.70 \%$ want to contribute funding. Including both funds and labor, farmers are willing to undertake $34.15 \%$ of total investment, and they think the rest should be undertaken by the government. 
Table 1. Descriptive statistics of sampling farmers.

\begin{tabular}{|c|c|c|c|}
\hline Items & & Quantity/ Person or Household & Rate $^{\#} / \%$ \\
\hline \multirow{4}{*}{ Householder Schooling } & Illiteracy & 7 & 2.53 \\
\hline & Primary School & 122 & 44.04 \\
\hline & Junior High School & 112 & 40.43 \\
\hline & Junior High School Above & 36 & 13.00 \\
\hline \multirow{2}{*}{ Annual Family Income } & $<40,000 \mathrm{RMB}$ & 170 & 61.37 \\
\hline & $\geq 40,000 \mathrm{RMB}$ & 107 & 38.63 \\
\hline \multirow{2}{*}{ Annual Agricultural Income } & $<6,000 \mathrm{RMB}$ & 188 & 67.87 \\
\hline & $\geq 6,000 \mathrm{RMB}$ & 89 & 32.13 \\
\hline \multirow{2}{*}{ Actual Cultivated Land } & $<0.3 \mathrm{hm}^{2}$ & 158 & 57.04 \\
\hline & $\geq 0.3 \mathrm{hm}^{2}$ & 119 & 42.96 \\
\hline \multirow{2}{*}{ Paddy Field } & $<0.2 \mathrm{hm}^{2}$ & 167 & 60.29 \\
\hline & $\geq 0.2 \mathrm{hm}^{2}$ & 110 & 39.71 \\
\hline \multirow{3}{*}{ Dry Farm } & $<0.1 \mathrm{hm}^{2}$ & 144 & 51.99 \\
\hline & $\geq 0.1 \mathrm{hm}^{2}$ & 133 & 48.01 \\
\hline & Mountain & 61 & 22.02 \\
\hline \multirow{3}{*}{ Type of Landform ${ }^{\dagger}$} & Hill & 85 & 30.69 \\
\hline & Mound & 20 & 7.22 \\
\hline & Plain & 145 & 52.35 \\
\hline \multirow{2}{*}{ Damage Condition of Irrigation Facilities } & Serious & 101 & 36.46 \\
\hline & Not Serious & 176 & 63.54 \\
\hline \multirow{2}{*}{ Farm Irrigation Condition } & Serious Shortage & 59 & 21.30 \\
\hline & Not Serious Shortage & 218 & 78.70 \\
\hline \multirow{2}{*}{ Private Irrigation Organization } & Existing & 15 & 5.42 \\
\hline & Not Existing & 262 & 94.58 \\
\hline \multirow{2}{*}{ Farmer Participation in Irrigation Organization } & Yes & 13 & 4.69 \\
\hline & No & 264 & 95.31 \\
\hline \multirow{2}{*}{$\begin{array}{l}\text { Farmer Willing to Participate in Construction of Small-scale Farmland } \\
\text { Water Conservation }\end{array}$} & Yes & 230 & 83.03 \\
\hline & No & 47 & 16.97 \\
\hline \multirow{2}{*}{ State of Trust in Village Cadres } & Trusted & 171 & 61.73 \\
\hline & Not Trusted & 106 & 38.27 \\
\hline \multirow{2}{*}{ Form of Participation in Construction ${ }^{\S}$} & Investing with Labor & 147 & 63.91 \\
\hline & Funding & 89 & 38.70 \\
\hline
\end{tabular}

Notes: \# Besides "Form of Participation in Construction", the divisor of the rate is 277 . $\dagger$ One region may have multiple types of landforms. $¥$ The degree of damage to irrigation facilities is defined as serious if the facilities fail to meet the basic demands of farmland irrigation. Otherwise, the damage is defined as not serious. § One household may have multiple forms of participation, so the divisor of the rate is 230.

Table 2. Statistical indexes of continuous variables.

\begin{tabular}{|c|c|c|c|c|c|}
\hline Variables & Obs. & Mean & Std. Dev. & Min. & Max. \\
\hline Percentage Willing to Invest in Irrigation & 277 & 28.37 & 19.36 & 0.1 & 80 \\
\hline Age of the Head of Household (Years) & 277 & 48.18 & 9.60 & 22 & 83 \\
\hline Household Head Schooling (Years) & 277 & 6.81 & 2.51 & 0 & 15 \\
\hline Annual Family Income (1,000 RMB) & 277 & 36.97 & 31.42 & 0 & 200 \\
\hline Percentage of Income from Agriculture & 277 & 28.36 & 30.75 & 0 & 100 \\
\hline Male Labor at Home Year-Round (Persons) & 277 & 0.66 & 0.67 & 0 & 6 \\
\hline Household Actual Cultivated Land / $0.1 \mathrm{hm}^{2}$ & 277 & 3.81 & 4.08 & 0 & 33.33 \\
\hline Percentage of Paddy Field & 277 & 60.54 & 33.82 & 0 & 100 \\
\hline
\end{tabular}

\section{Model Specification and Explanation of Variables}

The willingness of farmers to participate in small-scale water conservation has two parts: whether a farmer wants to participate at all and, once a farmer has decided to participate, how much the farmer is willing to invest. This paper uses the Heckman Model [23] [24] to answer these questions. The model contains two steps: the first step builds a binary selection model, and the second step uses Ordinary Least Squares (OLS), running a regression for participants, which contains an Inverse Mills Ratio $(\lambda)$ as a variable to judge the validity of the Heckman Model. The model does a good job of eliminating the effect of sample selection bias [25].

\subsection{Model Specification}

The Heckman Model includes two steps [23]. The first step is to build a Probit model of binary responses. It analyzes the farmer's decision to participate in water conservation. The equation may be denoted as [24]

$$
\operatorname{Pr}\left(Y_{1}=1\right)=\Phi(\zeta \boldsymbol{w})
$$

where $\operatorname{Pr}\left(Y_{1}=1\right)$ is the probability that a farmer is willing to participate in the construction of water conservation projects, 
$\boldsymbol{\zeta}$ is a vector of all parameters to be estimated, $\boldsymbol{w}$ is a vector of all explanatory variables, and $\Phi(\cdot)$ is a distribution function of a standard normal distribution. The regression equation is

$$
Y_{1 i}=\boldsymbol{\alpha} \boldsymbol{X}_{\boldsymbol{i}}+\boldsymbol{\beta} \boldsymbol{D}_{i}+\mu_{i}
$$

whose symbols are described as follows: a) The subscript $i$ represents an observation, i.e., a rural household; b) $Y_{1}$ is the dependent variable, taking the value of 1 if a farmer is willing to participate in the construction of water conservation, otherwise taking the value of $0 ;$ c) $\boldsymbol{\alpha}$ is a vector of parameters to be estimated, $\boldsymbol{\alpha}=\left(\alpha_{0}, \alpha_{1}, \cdots, \alpha_{8}\right)$; d) $\boldsymbol{X}$ is a vector of quantitative explanatory variables, $\boldsymbol{X}=\left(1, X_{1}, X_{1}^{2}, X_{2}, \cdots, X_{7}\right)^{\prime}$, where $X_{1}$ is the age of the head of a household (in years), $X_{2}$ is the years of schooling of the head of a household, $X_{3}$ is annual family income (in 1,000 RMB), $X_{4}$ is the ratio of agricultural revenue to total family income (\%), $X_{5}$ is the number of males under 50 years old who are at home year-round, $X_{6}$ is the actual cultivated land of a farmer (in $0.1 \mathrm{hm}^{2}$ ), and $X_{7}$ is the ratio of paddy field to total cultivated land (in \%); e) $\boldsymbol{\beta}$ is a vector of parameters to be estimated, $\boldsymbol{\beta}=\left(\beta_{1}, \beta_{2}, \beta_{3}\right)$; f) $\boldsymbol{D}$ is a vector of dummy explanatory variables, $\boldsymbol{D}=\left(D_{1}, D_{2}, D_{3}\right)^{\prime}$, where $D_{1}$ is the condition of farmland irrigation facilities, taking the value of 1 for serious shortage, i.e., the farmland water conservation facilities can't meet the basic demand for irrigation, otherwise taking the value of $0, D_{2}$ is the state of trust in village cadres, taking the value of 1 for trust, otherwise taking the value of 0 , $D_{3}$ is the state of farmer participation in an irrigation organization, such as a WUA, taking the value of 1 for having participated, otherwise taking the value of 0 ; and g) $\mu_{i}$ is a stochastic error term.

The second step is to analyze the effect of those factors on farmer participants' willingness to undertake a share of engineering construction, as the sum of funds and labor services, through the Ordinary Least Squares (OLS) method. The regression equation is

$$
Y_{2 i}=\gamma Z_{i}+\delta \boldsymbol{D} Z_{i}+\lambda \varphi(\zeta w) / \Phi(\zeta w)+\varepsilon_{i},
$$

whose symbols are described as follows: a) The subscript $i$ represents an observation; b) $Y_{2}$ is the dependent variable, i.e., the proportion of the cost of construction that a farmer deems that he and other villagers should undertake; c) $\gamma$ is a vector of parameters to be estimated, $\left.\gamma=\left(\gamma_{0}, \gamma_{1}, \cdots, \gamma_{5}\right) ; \mathrm{d}\right)$ $\boldsymbol{Z}$ is a vector of quantitative explanatory variables, $\boldsymbol{Z}=\left(1, X_{3}, \cdots, X_{7}\right)^{\prime}$; e) $\boldsymbol{\delta}$ is a vector of parameters to be estimated, $\boldsymbol{\delta}=\left(\delta_{1}, \delta_{2}, \delta_{3}\right)$; f) $\boldsymbol{D Z}$ is a vector of dummy explanatory variables, $\left.\boldsymbol{D Z}=\left(D_{1}, D_{2}\right)^{\prime} ; \mathrm{g}\right) \lambda$ is the Inverse Mills Ratio; h) $\varphi(\cdot)$ and $\Phi(\cdot)$ are the probability density function and distribution function of a standard normal distribution, respectively; $\varphi(\cdot) / \Phi(\cdot)$ is the correction term, $\boldsymbol{\zeta}=(\boldsymbol{\gamma}, \boldsymbol{\delta}), \boldsymbol{w}=\left(\begin{array}{c}\boldsymbol{Z} \\ \boldsymbol{D} \boldsymbol{Z}\end{array}\right)$; and i) $\varepsilon$ is a stochastic error term.

The Heckman Model requires that the explanatory variable set of the second step is a rigorous subset of that used in the first step [25]. From the foregoing, the above model specification meets this requirement.

\subsection{Explanation of Independent Variables}

The independent variables include three types: individual characteristics of the head of a household, characteristics of agricultural production, and characteristics of farmland water conservation and social environment.

(1) Individual characteristics of head of household. The individual characteristic variables only appear in the first step, i.e., the Probit model, which mainly considers three variables. The first two are the age of the head of a household and the age squared, $X_{1}$ and $X_{1}^{2}$. As the head of a household grows older, the probability of going away as a migrant worker decreases, and time spent at home in agriculture increases. When agricultural production time increases, the farmer is more dependent on agricultural income and farmland irrigation facilities. Hence, the farmer is more likely to participate in the construction of water conservation projects [5]. However, when he arrives at a certain age, his strength begins decreasing. The amount of time he spends on agricultural production is therefore reduced, so his probability of participating in the construction of water conservation projects decreases. The expected sign of $X_{1}$ is positive and that of $X_{1}^{2}$ is negative. The third variable is years of schooling of the household head, $X_{2}$. On the one hand, the more years of schooling the head of a household has, the higher the probability that he enters a non-agricultural sector. In that case, the farmer's willingness to participate in the construction of water conservation projects decreases. On the other hand, a high education level helps the head of a household understand the importance of farmland water conservation facilities, which results in the willingness increasing. Therefore, the effect of years of schooling of the household head is uncertain [20].

(2) Characteristics of agricultural production. This type of characteristic variable appears in both steps of the model. There are five variables: a) Annual family income, $X_{3}$. The higher the annual family income, the greater the ability of the family to undertake an investment. Therefore, annual family income leads to increased willingness to participate in construction. However, because high family income usually implies more nonfarm revenue than farm revenue, there is less motivation to invest in water conservation and therefore the willingness to participate decreases. Hence, the effect of annual family income is uncertain [21]. b) Ratio of agricultural revenue to family total income, $X_{4}$. On the one hand, the greater the percentage of agricultural revenue, the more the farmer depends on farmland irrigation, which will lead to willingness to invest in a greater proportion of the project cost. On the other hand, agriculture is more vulnerable 
than industry, which results in low agricultural revenue, and therefore a high percentage of family income from agriculture is associated with low total income. This budget constraint makes the farmer incapable of undertaking more irrigation investment. Hence, the effect of the ratio of agricultural revenue on willingness to participate is uncertain. c) Male labor under 50 years old at home year-round, $X_{5}$. For work requiring substantial labor intensity, such as digging sublateral canals and ponds, only male labor under 50 years old is generally capable. Therefore, male labor under 50 years old at home year-round is conducive to inputting labor into facilities construction, and the farmer's willingness to participate rises accordingly [22]. d) Actual cultivated land of farmer, $X_{6}$. Because average actual cultivated land is only $0.38 \mathrm{hm}^{2}$, and considering the variability of the independent variable and avoiding a singular matrix in the regression, $0.1 \mathrm{hm}^{2}$ is adopted as a unit of measurement of actual cultivated land. The more cultivated land a household has, the more benefit the farmer obtains from irrigation facilities. So, the farmer is more likely to take part in water conservation construction [5]. e) Ratio of paddy field to cultivated land, $X_{7}$. Because a unit area of paddy field consumes more water than does dry land, the paddy field is more dependent on water conservation facilities. Hence, the greater the percentage of paddy field, the greater the farmer's willingness to participate.

(3) Characteristics of farmland water conservation and social environment. There are three dummy variables, of which the first two appear in both steps and the last only appears in the first step. a) Farm irrigation conditions, $D_{l}$. Serious insufficiency of farmland irrigation would increase the farmer's willingness to take part in the construction of water conservation projects. However, when farmland irrigation is seriously insufficient, both the capital gap and labor gap for maintenance and dredging are very large. Because of the constraints of resources and capabilities, the farmer's willingness to undertake responsibility decreases [21]. b) State of village cadres trusted, $D_{2}$. Generally, rural construction of irrigation and water conservation projects is organized by village cadres. The higher the degree of trust in the cadres in the village, the stronger the willingness of farmers to take part in construction [26]. c) State of farmer participation in irrigation organizations, $D_{3}$. Private organizations such as WUAs voluntarily form to meet the irrigation demand of farmers. When problems occur in farm irrigation management and decisions, the organization may organize farmers at a low transaction cost [22]. Therefore, participation in a private irrigation organization helps raise the willingness of farmers to take part in the construction of small-scale farmland water conservation.

\section{Model Estimates and Analysis of Results}

Statistical software, Stata 12.0 , is used to estimate the Heckman Model. The regression results are shown in Table 3. The precondition for the validity of the Heckman Model is that the value of the Inverse Mills Ratio, $\lambda$, is nonzero and statistically significant [27]. The $\lambda$ value of the sample estimated is -25.347 and is statistically significant at the significance level of $10 \%$, so the Heckman Model is effective. The whole fitted statistic of the model, i.e., Wald $\operatorname{chi}^{2}(7)$, equals 14.161 , statistically significant at the significance level of $5 \%$, which shows the regression results are good as a whole.

Table 3. Results of Heckman Model estimated.

\begin{tabular}{|c|c|c|c|c|c|c|c|c|}
\hline \multirow{2}{*}{ Variables } & \multicolumn{4}{|l|}{$Y_{1}$} & \multicolumn{4}{|l|}{$Y_{2}$} \\
\hline & Coef. & Std. Err. & $z$ & $P>|z|$ & Coef. & Std. Err. & $z$ & $P>|z|$ \\
\hline $\mathrm{C}$ & -1.472 & 1.896 & -0.784 & 0.438 & $55.049^{* * * *}$ & 10.261 & 5.360 & 0.000 \\
\hline $\mathrm{X}_{1}$ & 0.034 & 0.067 & 0.509 & 0.613 & - & - & - & - \\
\hline$X_{1}^{2}$ & -0.000 & 0.001 & -0.602 & 0.549 & - & - & - & - \\
\hline $\mathrm{X}_{2}$ & $0.084^{* *}$ & 0.047 & 1.799 & 0.072 & - & - & - & - \\
\hline $\mathrm{X}_{3}$ & -0.001 & 0.003 & -0.362 & 0.716 & $0.106^{* *}$ & 0.56 & 1.881 & 0.060 \\
\hline $\mathrm{X}_{4}$ & 0.004 & 0.004 & 0.981 & 0.329 & -0.026 & 0.065 & -0.409 & 0.681 \\
\hline $\mathrm{X}_{5}$ & 0.207 & 0.156 & 1.325 & 0.185 & -2.709 & 2.603 & -1.041 & 0.298 \\
\hline $\mathrm{X}_{6}$ & $0.107^{* * *}$ & 0.044 & 2.436 & 0.015 & -0.001 & 0.504 & -0.000 & 0.999 \\
\hline $\mathrm{X}_{7}$ & 0.002 & 0.003 & 0.824 & 0.415 & $-0.128^{* * * *}$ & 0.049 & -2.592 & 0.010 \\
\hline $\mathrm{D}_{1}$ & $0.832^{* * * *}$ & 0.313 & 2.647 & 0.008 & $-7.311^{*}$ & 4.863 & -1.503 & 0.133 \\
\hline $\mathrm{D}_{2}$ & $0.648^{* * * *}$ & 0.203 & 3.183 & 0.001 & $-9.132^{* * *}$ & 4.571 & -2.001 & 0.046 \\
\hline $\mathrm{D}_{3}$ & -0.392 & 0.448 & -0.884 & 0.382 & - & - & - & - \\
\hline$\lambda$ & - & - & - & 一 & $-25.347^{* *}$ & 13.236 & -1.922 & 0.055 \\
\hline rho & -1.000 & sigma & 25.346 & Wald $\operatorname{chi}^{2}(7)$ & 14.161 & Prob $>$ chi $^{2}$ & $0.048^{* * *}$ & \\
\hline
\end{tabular}

Notes: ${ }^{* * * *},{ }^{* * *},{ }^{* *}$ and ${ }^{*}$ show the variables are statistically significant at the significance level of $1 \%, 5 \%, 10 \%$ and $15 \%$, respectively.

\subsection{Factors That Influence the Willingness of Farmers to Participate in the Construction of Small-Scale Farmland Water Conservation Projects}

The dependent variable of the first step of the Heckman Model is a two-valued variable, whose estimated parameters only show the directions of the effects of the explanatory variables on the dependent variable, i.e., the willingness of farmers to participate in the construction of small-scale farmland water conservation projects, but not the marginal effects. The signs of the head of a household's age, $X_{1}$, and its square, $X_{1}^{2}$, are positive and negative, respectively, which is consistent with expectations, but neither variable is statistically significant. The years of schooling of the head of a household, $X_{2}$, has a significant positive effect on the 
farmer's willingness to participate. When the number of years of school is greater, it has an influence on the cognition of the importance of improving irrigation, significantly more than it does on labor migration. The sign of annual family income, $X_{3}$, is negative, but not significant. With family income increasing, on the one hand, the capability of a farmer to undertake construction projects increases; on the other hand, due to the dominance of non-agricultural income in a high-income family, the household is less dependent on agricultural income. This finding suggests that one of these effects (the reduced importance of agriculture in a higher-income family) outweighs the other (the greater capacity of a higher-income family to invest in conservation), but the integrated effect is not significant. The sign of the ratio of agricultural revenue to family income, $X_{4}$ is positive, which is consistent with expectations, but not significant. The higher the ratio of agricultural revenue, the greater the demand of the farmer for irrigation. But the low yield of agriculture has the result that the farmer is incapable of investing in irrigation, which makes the variable non-significant. The sign of male labor below 50 years old at home year-round $\left(X_{5}\right)$ and the sign of the ratio of paddy field to arable land $\left(X_{7}\right)$ are positive, consistent with expectations, but neither of the variables is significant. The sign of the actual cultivated area, $X_{6}$, is positive and significant at the $5 \%$ significance level. The larger the cultivated area, the greater the irrigation demand, so the farmer's willingness to participate increases. The signs of the condition of farm irrigation $\left(D_{1}\right)$ and the state of trusting village cadres $\left(D_{2}\right)$ are positive, consistent with expectations, and significant at the $1 \%$ significance level. Both serious insufficiency of irrigation and the state of trusting the village cadres can significantly improve the probability of a farmer participating in construction. The sign of the farmer taking part in a private irrigation organization, $D_{3}$, is negative, consistent with expectations, but not significant. Since there are only a few private irrigation organizations in Hubei Province, i.e., about $6 \%$ of villages have such an organization, their function is not perceived as important by the farmers. Hence, the effect of this variable is not significant.

\subsection{Factors That Influence Farmers' Willingness to Invest in Water Conservation-Testing the Theoretical Propositions}

Because the second step of the Heckman Model adopts the OLS method, the estimated coefficients measure the marginal effects of the explanatory variables on the dependent variable, i.e., farmers' willingness to invest in water conservation. The survey question is: "What percentage of irrigation and water conservation input should the village residents as a whole undertake?" A reasonable assumption is that an individual farmer's willingness to invest a certain proportion is positively correlated with his perceptions of the obligations of the village residents as a whole. The influence of independent variables and the results of testing the above six theoretical propositions are shown as follows.

(1) Prop. 1: The higher the farmer's income, $M_{k}$, the more he invests in small-scale farmland water conservation. Annual family income, $X_{3}$, is significant at the $10 \%$ significance level. On average, when income increases by $1,000 \mathrm{RMB}$, the farmer is willing to increase investment in water conservation by $0.106 \%$, which shows Prop. 1 is true.

(2) Prop. 2: The greater the value of $a / b$ (where $a$ is the commodity demand elasticity of utility and $b$ is the irrigation demand elasticity of utility), the less the farmer invests in water conservation. Because only the issue of small-scale farmland water conservation is discussed, $a$ is supposed constant. According to the law of diminishing marginal utility, if the stock of water conservation is insufficient, which is characterized by the status of farm irrigation, $D_{l}$, a $1 \%$ increase in investment in water conservation leads to farmer utility increasing by a greater percentage; hence, the value of $b$ increases. When $b$ increases, $a / b$ decreases. Variable $D_{l}$ is significant at the $15 \%$ significance level. Compared with no serious deficiency in irrigation, a serious deficiency causes farmers' willingness to invest to decrease by $7.311 \%$. When the stock of water conservation facilities is low, that is, the necessary investment in construction is large, the farmer is willing and able to undertake a proportion that is naturally decreasing. When irrigation is in a state of serious shortage, the value of $b$ is large, i.e., the value of $a / b$ is small. However, the result of the empirical analysis is that the proportion of farmer investment decreases. So, Prop. 2 is not true.

(3) Prop. 3: The higher the price of small-scale farmland water conservation, $p_{h}$, the less the farmer invests in it. Since $p_{h}$ is equal to the construction cost of small-scale farmland water conservation divided by the increment of water conservation facilities, $p_{h}$ is positively related to serious irrigation deficiency, $D_{l}$. The sign of $D_{l}$ is negative and statistically significant, which shows that, when irrigation is seriously insufficient, the value of $p_{h}$ is high and the farmer invests less. Hence, Prop. 3 is true.

(4) Prop. 4: The greater the impact factor of the farmer, $l_{k}$, the more the farmer invests in small-scale farmland water conservation. The impact factor of the farmer, $l_{k}$, is characterized by the male labor under 50 years old at home year-round $\left(X_{5}\right)$, actual cultivated area $\left(X_{6}\right)$ and the ratio of paddy field, $X_{7}$. Specifically, $l_{k}$ is positively related to variables $X_{5}, X_{6}$ and $X_{7}$. The signs of $X_{5}, X_{6}$ and $X_{7}$ are all negative, of which $X_{5}$ and $X_{6}$ are not significant, and $X_{7}$ is significant at the $1 \%$ significance level. When the proportion of paddy field increases by $1 \%$, i.e., the impact factor of the farmer increases, the farmer's willingness to undertake a proportion of investment decreases by $0.128 \%$, which shows Prop. 4 is not true.

(5) Prop. 5: The greater the sum of other farmers' input,, the original stock of water conservation in the village, $H_{0}$, and the current investment of government, $G_{0}$, the less the farmer invests in small-scale farmland water conservation. The other farmers' input, the original stock of water conservation in the village and the investment of government are characterized by the irrigation status, $D_{1}$. The variable $D_{1}$ is significant at the $15 \%$ significance level. In the case of a serious shortage of water conservation facilities, the sum of the other farmers' 
input, the original stock of water conservation in the village and the investment of government is less than that sum in the case of no serious shortage, with the result that the percentage of farmer's investment decrease by $7.311 \%$. So, Prop. 5 is not true.

(6) Prop. 6: The assumption of $a+b \leq 1$ fails. The Wald test shows the assumption of $a+b \leq 1$ fails at the $1 \%$ significance level.

In addition, the ratio of agricultural income to total family income, $X_{4}$, is not significant. Trust in village cadres, $D_{2}$, is significant, but its sign is negative, which is inconsistent with expectations. Compared with untrusted village cadres, trust in the village cadres makes the farmer's input decrease by $9.132 \%$. This may be explained if, given that the government has made an investment in water conservation, the farmer trusts that the village cadres will improve management efficiency and decrease operation costs, so there is decreasing room for farmers' investment.

\section{Discussion}

According to the above testing of the theoretical propositions, it is necessary to discuss them as follows:

Firstly, Prop. 1 (the higher the farmer's income, the more he invests in small-scale farmland water conservation) and Prop. 3 (the higher the price of small-scale farmland water conservation, the less the farmer invests in it), are proven true, which is consistent with the results of other work [5]. However Prop. 2 (the greater the value of $a / b$, the less the farmer invests in small-scale farmland water conservation), Prop. 4 (the greater the impact factor of farmers, the more the farmer invests in small-scale farmland water conservation), and Prop. 5 (the greater the sum of other farmers' input, the original stock of water conservation in the village and the current investment of government, the less the farmer invests in small-scale farmland water conservation) are proven not true. The reasons may be related to the data selection pattern, i.e., encounter sampling, which is not random sampling, and the attempt to prove these propositions indirectly rather than directly. Hence, a follow-up study should be conducted using improved randomness of data collection and perfection of the theoretical framework.

Secondly, the theoretical assumption of other work, i.e., $a+b \leq 1$ [22], is relaxed and is rejected by the empirical research. Hence, Prop. 6 is true. It is shown that the construction of farmland water conservation may promote farmers' overall benefits. Establishing private organizations, such as WUAs, according to local practice should be a more effective pattern of farmers' PIM. It may effectively organize individual villagers to participate in the construction of irrigation facilities, and may provide villagers with organization when they collectively express their appeals to government departments.

\section{Conclusions}

Based on the Heckman Model, using survey data of a major grain producing area, Hubei Province, we analyze the factors that influence the willingness of farmers to participate in small-scale farmland water conservation. It is not difficult to conclude and make corresponding suggestions as follows:

Firstly, years of schooling of the head of a household, actual cultivated area and serious lack of irrigation significantly promote farmers' willingness to participate in small-scale farmland water conservation construction. This is consistent with other results [5] [22]. It is important to note that more years of schooling of the head of a household makes it more likely that rural households are willing to participate in farmland water conservation construction. Therefore, all levels of government should pay attention to rural education. In particular, the government should provide specialized training for farmers, with content promoting farmers' understanding of the importance of water conservation and water conservation projects, routine maintenance methods of irrigation facilities, the techniques and skills of water saving, etc.

Secondly, farmers' trust in the village cadres significantly decreases the percentage of the cost of water conservation projects that farmers are willing to contribute. This result is different from other studies [5]. The farmers might perceive that, given the level of farmland water conservation, enterprising village cadres may decrease total costs, and thus the farmers' decreased investment won't affect farmland irrigation. Because village cadres may influence the operating cost of farmland water conservation facilities and the efficiency of the use of government financing for water conservation, the selection of village cadres should follow the principle of people being appointed on their merits. Rural elites who are capable and responsible should fill the important posts of village cadres.

\section{Acknowledgements}

This work was supported by Humanities and Social Sciences Project of Hubei Education Department (16Y190 and Q20162907), Huang Gang City College-enterprise Cooperation Project (2016000411) and Huang Gang Normal University Projects (201610303, zxfz2016B033 and 2016CE25).

\section{References}

[1] National Bureau of Statistics of China, China statistical abstract 2015. Beijing: China Statistics Press, 2016.

[2] S. Jia, S. Lin, and A. Lv, "Will China's water shortage shake the world's food security?" Water International, 2010, vol. 35, no. 1, pp. 6-17.

[3] X. Luo, "A study on the policy changes in farmland water conservation in the new China," Exploration and Discussion, 2011, no. 8, pp. 43-46. (in Chinese).

[4] X. He and L. Guo, "Farmland water conservation and its cost and benefit analysis," Management World, 2010, no. 7, pp. 86-97. (in Chinese). 
[5] X. Hu, "Research on farmers' willingness to participate in small-scale scale irrigation systems management and maintenance," Yangling: North West Agriculture and Forestry University, 2013. (in Chinese).

[6] F. J. Convery, "Reflections - Shaping water policy: What does economics have to offer," Review of Environmental Economics and Policy, 2013, vol. 7, no. 1, pp. 156-174.

[7] J. Berbel and J. A. Gómez-Limón, "The impact of water-pricing policy in Spain: An analysis of three irrigated areas," Agricultural Water Management, 2000, vol. 43, no. 2, pp. 219-238.

[8] F. A. Aregay, M. Zhao, and Z. M. Bhutta, "Irrigation water pricing policy for water demand and environmental management: A case study in the Weihe River basin," Water Policy, 2013, vol. 15, no. 5, pp. 816-829.

[9] F. Bartolini, V. Gallerani, M. Raggi, and D. Viaggi, "Water management and irrigated agriculture in Italy: Multicriteria analysis of alternative policy scenarios," Water Policy, 2010, vol.12, no. 1, pp. 135-147.

[10] M. W. Rosegrant and C. Ringler, "Impact on food security and rural development of transferring water out of agriculture," Water Policy, 2000, vol. 1, no. 6, pp. 657-586.

[11] E. Ostrom, "Collective action and the evolution of social norms," Journal of Economic Perspectives, 2000, vol. 14, no. 3, pp. 137-158.

[12] P. Bardhan, "Analytics of the institutions of informal cooperation in rural development," World Development, 1993, vol. 21 , no. 4 , pp. 633-639.

[13] A. Sarker and T. Itoh, "Design principles in long-enduring institutions of Japanese irrigation common-pool resources," Agricultural Water Management, 2001, vol. 48, no. 2, pp. 89-102.

[14] L. R. Brown and B. Halweil, "China's water shortage could shake world food security," World Watch, 1998, vol. 11, no. 4, pp. 10-21.

[15] Q. Huang, D. Dawe, S. Rozelle, et al, "Irrigation, poverty and inequality in rural China," Australian Journal of Agricultural and Resource Economics, 2005, vol. 49, no. 2, pp. 159-175.
[16] E. Ostrom, Crafting institutions for self-governing irrigation systems, San Francisco: Institute for Contemporary Studies Press, 1992.

[17] M. S. Gheblawi, Estimating the value of stochastic irrigation water deliveries in Southern Alberta: A discrete sequential stochastic programming approach, Edmonton: University of Alberta, 2004.

[18] J. A. van Ast and S. P. Boot, "Participation in European water policy," Physics and Chemistry of the Earth, Parts A/B/C, 2003, vol. 28, no. 12-13, pp. 555-562.

[19] R. Meinzen-Dick, "Groundwater markets in Pakistan: Participation and productivity," Research Report 105. IFPRI, Washington D C, 1996.

[20] X. Kong and B. Shi, "Analysis of factors affecting farmers' willingness to participate in WUAs," Chinese Rural Economy, 2008, no.10, pp. 22-33. (in Chinese).

[21] H.Xu and X. Huang, "A study on land use policy and farmers' willingness to participate in the management of saline-alkaline land farmland irrigation," China Demographics, Resources and Environment, 2014, vol. 24, no. 3, pp. 154-160. (in Chinese).

[22] H. Liu and S. Chen, "Empirical analysis of factors affecting farmers' willingness to participate in small-scale farmland water conservation construction," Chinese Rural Survey, 2012, no. 2, pp. 54-66. (in Chinese).

[23] J. J. Heckman, "Sample Selection Bias as a Specification Error," Econometrica, 1979, vol. 47, no. 1, pp. 153-161.

[24] W. H. Greene, Econometric analysis, 5th ed., Englewood Cliffs: Prentice-Hall, 2003.

[25] J. M. Wooldridge, Introductory econometrics: A modern approach, 5th ed., Toronto: Cengage Learning, 2013.

[26] K. Wang, C. Wang, and H. Yu, "A study on the mechanism of farmer participation in management and decisions in farmland water conservation projects," Rural Economy, 2011, no. 9, pp. 92-95. (in Chinese).

[27] Y. Tan and Y. Yuan, "Analysis of the effects of loyalty and wage of the insurance salesman," Insurance Professional School Acta, 2013, vol. 27, no. 4, pp. 28-34. (in Chinese). 